\title{
Experimental study and modelling of water sorption/desorption isotherms on two agricultural products: Apple and carrot
}

\author{
S. Timoumi ${ }^{1}$, F. Zagrouba ${ }^{1}$, D. Mihoubi ${ }^{1}$ and M.M. Tlili $^{2}$ \\ ${ }^{1}$ Laboratoire d'Énergétique et des Procédés Thermiques, Institut National de Recherche \\ Scientifique et Technique, BP. 95, 2050 Hammam-Lif, Tunisie \\ ${ }^{2}$ Laboratoire de Géochimie et de Physico-Chimie de l'Eau, Institut National de Recherche \\ Scientifique et Technique, BP. 95, 2050 Hammam-Lif, Tunisie
}

\begin{abstract}
This work is focused on some properties of dried apple (Red Chief) and carrot (Misky). Water sorption isotherms of carrot and apple were investigated at three temperatures: 30,40 and $60^{\circ} \mathrm{C}$, corresponding to drying temperatures, by the static method consisting of the use of different sulphuric acid solutions. Guggenheim-Anderson-de Boer (G.A.B) model is found to describe the experimental curves better than Henderson, Hasley and Oswin models with a correlation coefficient superior to 0.97 for both products. The hysteresis phenomenon was clearly observed in the case of apple isotherms. The experimental data were also used to determine the isosteric enthalpy of desorption of apple and carrot. The isosteric enthalpy of desorption decreased with increase in moisture content and the trend became asymptotic.
\end{abstract}

\section{INTRODUCTION}

The quality of agricultural products as a result of drying depends on the specifics of the drying process (temperature, air velocity, humidity, etc.). Therefore the knowledge of sorption/desorption characteristics is the starting point for the investigation of quality variation during drying and storage processes and indispensable to food product and process development, food engineering and industrial quality control. Much information can be found in literature and also some collections of data were built but little equilibrium data about apple and carrot can be found. The aim of this study was to establish experimental sorption/desorption isotherms at three temperatures $\left(30,40\right.$ and $\left.60^{\circ} \mathrm{C}\right)$. Other objectives include the evaluation of the ability of four models to fit the data obtained, and the determination of the isosteric enthalpy of desorption of the product using its moisture sorption isotherms.

\section{MATERIAL AND METHOD}

Fresh samples served for this study: carrots (misky) and apple (red chief) were collected from Tunisian market. The equilibrium moisture content of these two products at different temperatures was determined by the means of the static method consisting of the use of different sulphuric acid solutions. Samples are firstly cut in a cub shape (apple) and cylinder shape (carrot) and their initial weight is determined $(1 \pm 0.1 \mathrm{~g})$. For the desorption process, samples are directly introduced in little baskets in the glass containers above the sulphuric acid solutions where the relative humidity was 
fixed by the sulphuric acid solution. For the adsorption process, samples are dehydrated in the regulated oven at a temperature of $70^{\circ} \mathrm{C}$ until reaching constant weight before putting in the glass jars. The whole are put in an oven adjusted to a stationary temperature of 30,40 and $60^{\circ} \mathrm{C}$. For each temperature, samples are weighted every two days. When samples reach a constant weight, equilibrium moisture content is acknowledged. The final moisture content of each sample is determined by using an air oven method at $105^{\circ} \mathrm{C}$ for 6 to $8 \mathrm{~h}$ until sample masses do not vary anymore with time. The difference of mass before and after drying at $105^{\circ} \mathrm{C}$ gives the moisture content $\mathrm{X}_{\mathrm{eq}}$ of the product at hygroscopic equilibrium.

$$
\mathrm{X}_{\mathrm{eq}}=\frac{\mathrm{m}_{\mathrm{W}}-\mathrm{m}_{\mathrm{d}}}{\mathrm{m}_{\mathrm{d}}}
$$

Where $m_{w}$ is the mass of wet matter and $m_{d}$ is the mass of dry matter.

\section{RESULTS AND DISCUSSION}

\subsection{Experimental results}

The sorption isotherms of our two agricultural products, at different temperatures, show a sigmoid shape corresponding to type II of the classification of Brunauer et al., [1]. This behaviour is typical for many food products $[2,3,4,5]$.
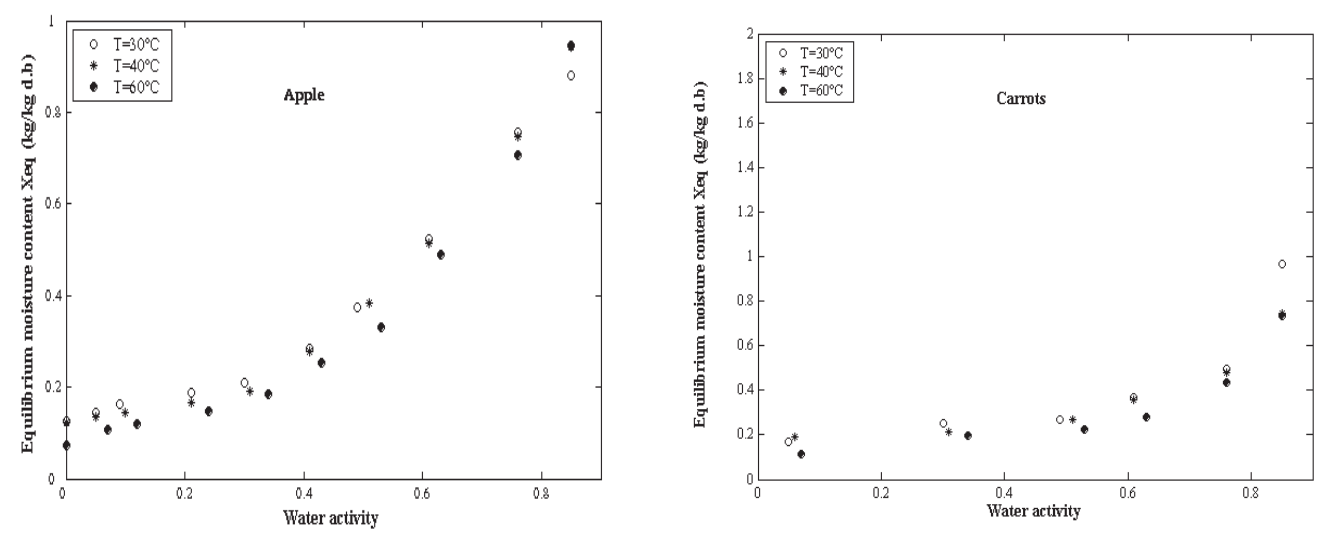

Figure 1. Desorption isotherms.

Temperature affects the mobility of water molecules and the dynamic equilibrium between the vapour and adsorbed phases. Figure 1 illustrates the effect of temperature shift on the desorption phenomena. At a constant water activity, an increase in temperature leads to a decrease in the amount of sorbed water indicating that the material becomes less hygroscopic. The increase of temperature is then an unfavourable condition to water sorption. An exception to this rule applies to certain sugars and other low molecular weight constituents, which become more hygroscopic at higher temperatures because they dissolve in water [6]. As shown in figure 1, an increase of temperature causes an increase of water activity for the same moisture content. Similar results have been reported in the literature $[7,8,9]$. The intersection (inversion) point depends on the composition of the material and the solubility of sugars. The amount of sugar decides whether inversion occurs or not. In fact, 
for products with low sugar content the isotherms do not intersect with increased temperature [10]. As sugar content in apple is higher than in carrot isotherms intercept rapidly than the carrot isotherms.

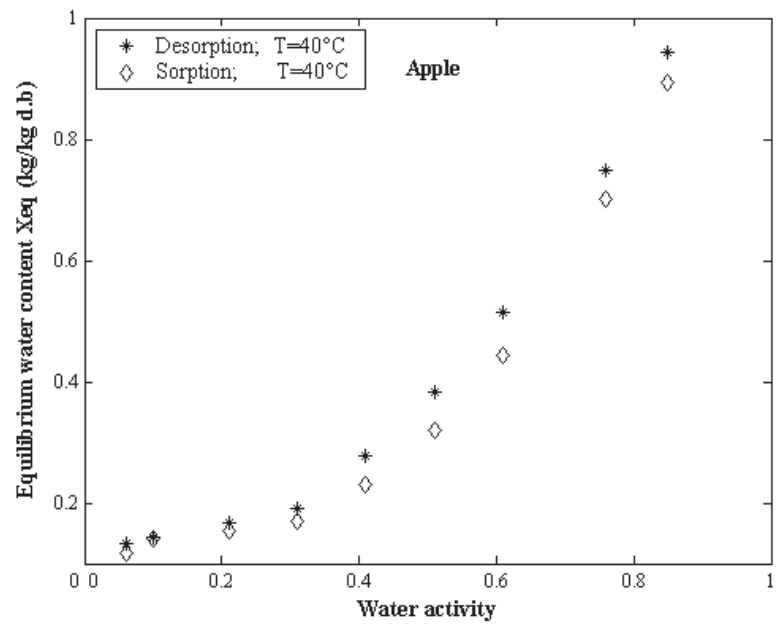

Figure 2. Hysteresis effect at $\mathrm{T}=40^{\circ} \mathrm{C}$ (apple).

The hysteresis effect was observed for apple isotherms and the figure 2 illustrates this phenomenon registered for $40^{\circ} \mathrm{C}$. This gap between adsorption and desorption is not yet fully explained. However, some authors attribute this phenomenon to the physical change of the material as caused by the loss of water.

\subsection{Modelling}

To model sorption isotherms curves, several empirical and semi-empirical equations have been proposed for the correlation of the equilibrium moisture content with the equilibrium relative humidity of the air surrounding the food product. Among these equations, we chose four equations as follow:

$$
\begin{array}{ll}
X_{\text {eq }}=\frac{\mathrm{abca}_{\mathrm{w}}}{\left(1-\mathrm{ca}_{\mathrm{w}}\right)\left(1+(\mathrm{b}-1) \mathrm{ca}_{\mathrm{w}}\right)} & \text { G.A.B } \\
\mathrm{X}_{\mathrm{eq}}=\left[\frac{-\ln (\mathrm{a}+\mathrm{bT})}{\ln \left(\mathrm{a}_{\mathrm{w}}\right)}\right]^{\frac{1}{\mathrm{c}}} & \text { Modified Hasley } \\
X_{\text {eq }}=10^{-2}\left[-\frac{1}{\mathrm{a}(\mathrm{T}+\mathrm{c})} \ln \left(1-\mathrm{a}_{\mathrm{w}}\right)\right]^{\frac{1}{b}} & \text { Modified Henderson } \\
X_{\text {eq }}=(\mathrm{a}+\mathrm{bT})\left[\frac{\mathrm{a}_{\mathrm{w}}}{1-\mathrm{a}_{\mathrm{w}}}\right]^{\frac{1}{c}} & \text { Modified Oswin }
\end{array}
$$

$\mathrm{a}, \mathrm{b}$ and $\mathrm{c}$ are characteristic parameters and $\mathrm{a}_{\mathrm{w}}$ is the water activity.

$\mathrm{R}$ : perfect gas constant.

A comparison between ability of equations is reported in figure 4. The greatest deviation for almost all the models was observed at low water activity values. GAB model is found to fit the experimental 
curves (figures 3 and 4) better than modified Oswin, modified Hasley and Henderson models. Literature reports that GAB model shows a very good behaviour with sigmoid shaped sorption isotherms typical for most food products $[2,5,7]$. Finally it can be noted that sorption isotherms are specific to the product and their experimental determination is often indispensable.
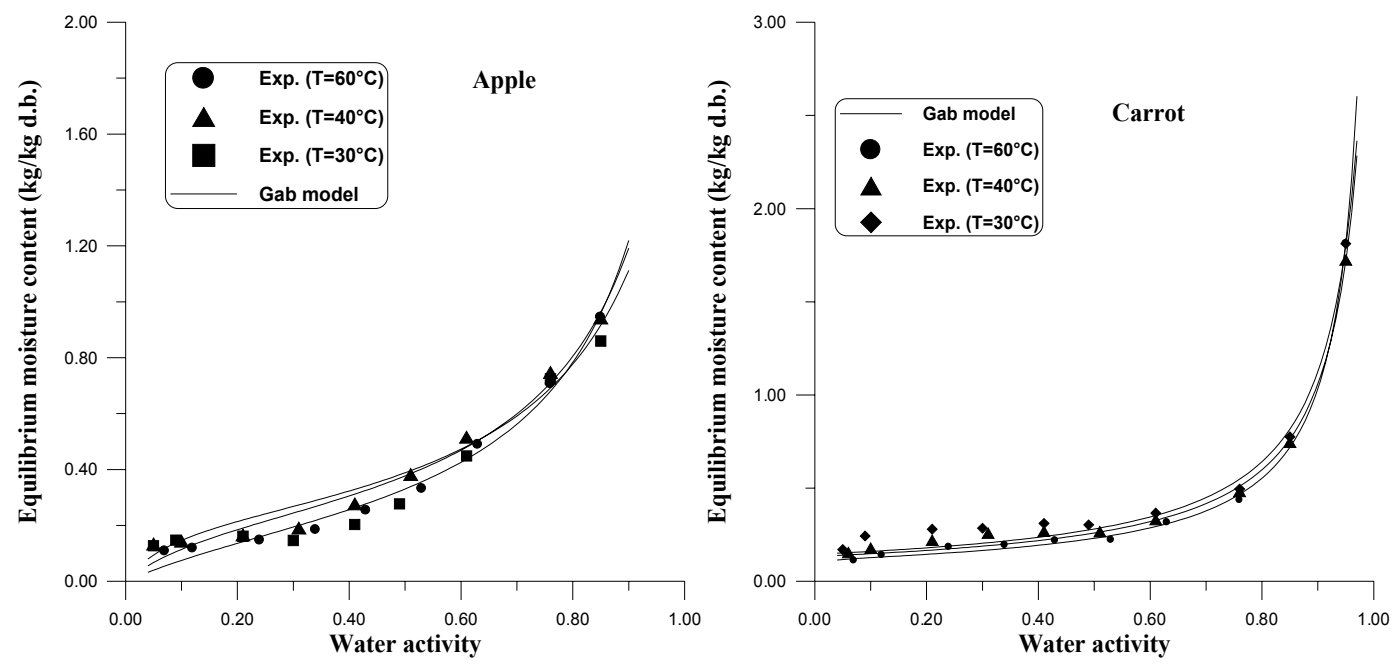

Figure 3. Desorption isotherms fitted with GAB model.
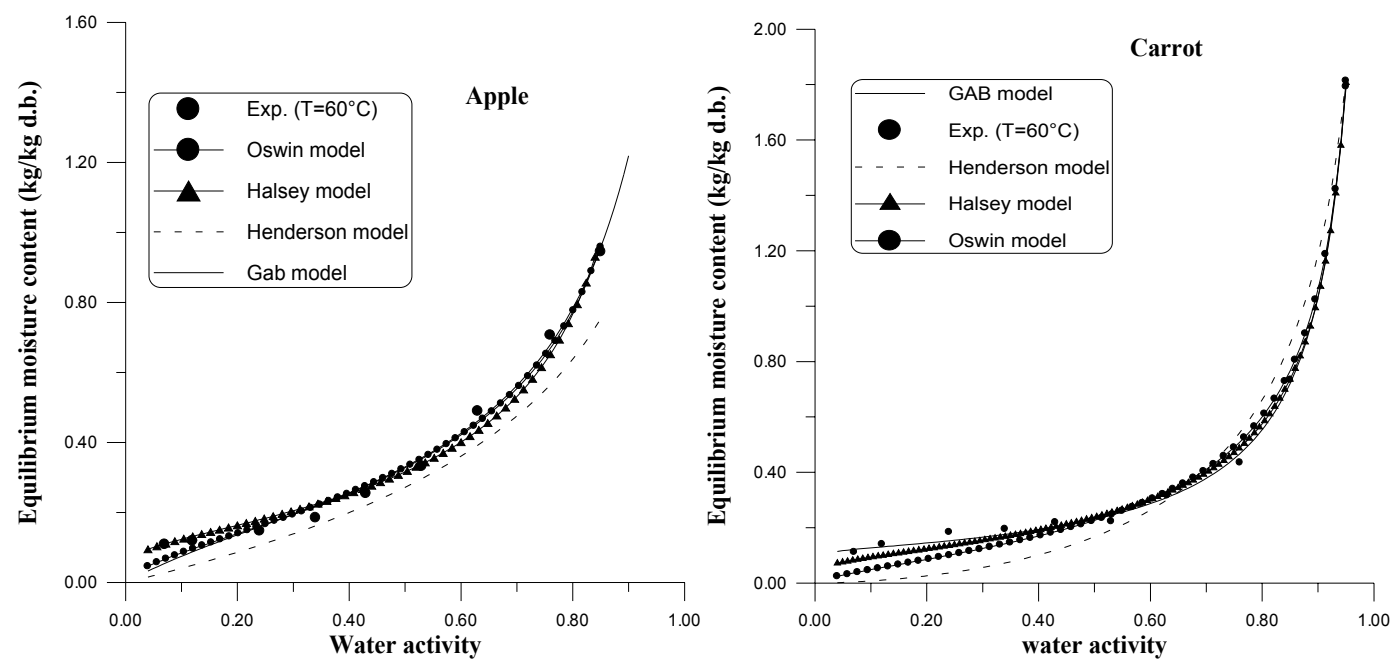

Figure 4. Desorption isotherms $\left(60^{\circ} \mathrm{C}\right)$ fitted with different models.

\subsection{Sorption enthalpy and entropy}

When water vapour is adsorbed on a surface, a quantity of heat, the heat of adsorption, is released. When adsorbed water vapour is desorbed, a quantity of heat is taken up, the heat of desorption, and is a measure of the heat or energy that must be added to adsorbed water to break the intermolecular force. The enthalpy of adsorption or desorption indicates the binding energy or the intermolecular force between the molecules of water vapour and the surface of absorbent. 
The isosteric enthalpy of desorption was determined from Clasius Clapeyron equation:

$$
\left(\frac{\partial \ln \mathrm{P} / \mathrm{P}^{\mathrm{O}}}{\partial\left(\frac{1}{\mathrm{~T}}\right)}\right)_{X}=-\frac{\Delta \mathrm{H}_{S}}{\mathrm{R}}
$$

$\Delta \mathrm{H}_{\mathrm{S}}$ is the isosteric enthalpy of desorption.

Therefore, the isosteric enthalpy of desorption $\Delta \mathrm{H}_{\mathrm{S}}$ at any value of water content, can be evaluated graphically by plotting the sorption isostere, as $\ln \mathrm{P} / \mathrm{P}^{\mathrm{O}}$ versus $1 / \mathrm{T}$. The isosteric heat $\left(\mathrm{Q}_{\mathrm{S}}\right)$ is then equal to $\Delta \mathrm{H}_{\mathrm{S}}+\Delta \mathrm{H}_{\mathrm{V}}$ where $\Delta \mathrm{H}_{\mathrm{V}}$ is the heat of water vaporisation.

Values of determined desorption isosteric enthalpy according to the product water content are presented in figure 5 .
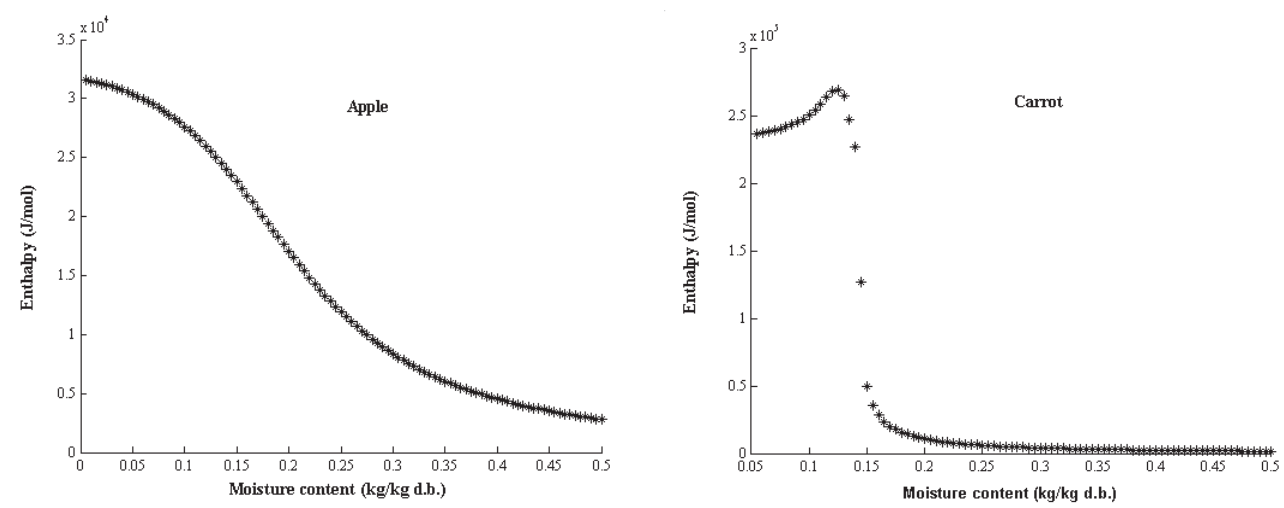

Figure 5. The isosteric enthalpy of desorption.

We note that the desorption enthalpy increases when the water content decreases. In fact, at the beginning of drying, the product is reach with free water easy to remove. Whereas, for low water content, we evaporate water molecules corresponding to the strongest interactions. Therefore the corresponding desorption enthalpy and the heat of sorption are high. Similar results have been reported for other products $[2,5,8]$. The reduction of the energy of water link in carrots shown in figure 5 for less than $0,14 \mathrm{~kg}$ of water by $\mathrm{kg}$ of dry basis (d.b), results probably from the relaxation phenomena and transition of phases associated to this weak mobility of water.

\section{CONCLUSION}

The equilibrium moisture content of apple and carrot was experimentally determined at 30, 40 and $60^{\circ} \mathrm{C}$ over a wide range of water activities. The behaviour was, as expected, the following: sorbed water decreases while the temperature increases at constant water activity. The hysteresis effect was registered only for apple isotherms. Experiments are performed and data are used to determine the best models for predicting the desorption equilibrium moisture content of carrot and apple for known values of temperature and relative humidity. The isosteric enthalpy and entropy were estimated indicating the presence of bound water for low moisture content values. 


\section{References}

[1] Brunauer, S.; Deming, L.S.; Deming W.E.; Teller, E. On a theory of the Van Der Waals adsorption of gases, Journal of American Chemical Society,1940, 62, 7, 1723-1732.

[2] Ajibola O.O., Aviara N.A., Ajetumobi O.E. Sorption equilibrium and thermodynamic properties of cowpea (Vigna unguiculata). Journal of Food Engineering, 2003, 58 : 317-324.

[3] Delgado, A.E.; Sun, D.W. Desorption isotherms and glass transition temperature for chicken meat. Journal of Food Engineering, 2002, 55, 1-8.

[4] Giovanelli, G.; Zanouni, B.; Lavelli, V.; Nani, R. Water sorption, drying and antioxydant properties of dried tomato products. Journal of Food Engineering. 2002, 52, 135-141.

[5] Vazquez G., Chenlo F. and Moreira R. Sorption isotherms of lupine at different temperatures. Journal of Food Engineering, 2003, $60: 449-452$.

[6] Wladyslaw, K.; Tadeusz, K. Equilibrium moisture relation for foods and bio-materials. In drying technology in agriculture and food science. Arun S. Mujumdar (Ed.) Science Publishers Inc, 2000.

[7] Lahsasni, S.; Kouhila, M.; Mahrouz, M.; Kechaou, N. Experimental study and modelling of adsorption and desorption isotherms of prickly pear peel (Opuntia ficus indica). Journal of Food Engineering, 2002, 55, 201-207.

[8] Sobral, P.A.; Lebert, A.; Bimbenet, J.J. Isothermes de désorption de la pomme de terre entre 40 et $70^{\circ}$ C. Sciences des Aliments, 1999, 19, 711-720.

[9] Timoumi S., Mihoubi D., Zagrouba F. et Ben Amor M., 2003. Experimental study and modelling of adsorption/desorption isotherms of two agricultural products: apple and carrot. $4^{\text {th }}$ European Congress of chemical engineering, Espagne, Septembre 2003.

[10] Roman G.N., Urbicain M.J., Rostein E. Moisture equilibrium in apples at several temperatures: experimental data and theoretical considerations, Journal of Food Science, 1982, 47, 5, 1484$1488,1507$. 